\title{
Cotidiano e Identidade na Clínica da Atividade e na Ergologia
}

Cotidiano e Identidad en la Clínica de la Actividad y en la Ergología

Everyday life and Identity in the Clinic of Activity and Ergology

Carlos José Naujorks

Universidade Federal de Santa Catarina - Santa Catarina - Brasil

\section{RESUMO}

O presente artigo tematiza a presença dos conceitos cotidiano e identidade nas abordagens clínicas do trabalho designadas como Clínica da Atividade e Ergologia e propõe uma análise da relevância metodológica desses conceitos para a investigação de situações concretas de trabalho. Argumenta-se que muito embora os conceitos em questão não constituam conceitos-chave nas teorias em análise, eles apresentam aspectos fundamentais dessas abordagens. As Clínicas do Trabalho, particularmente as abordagem enfocadas, partem da distinção entre as dimensões prescrita e real do trabalho, compreendendo a atividade como as possibilidades de ação do sujeito frente às prescrições do trabalho e aos diversos elementos que compõe os processos de trabalho e o contexto organizacional. Essas possibilidades de ação que caracterizam a atividade acontecem no cotidiano do trabalho e mobilizam recursos identitários próprios a cada sujeito. Assim, ao evidenciar a importância das noções de cotidiano e identidade pretende-se contribuir tanto com o desenvolvimento teórico dos estudos sobre clínica do trabalho quanto para suas metodologias de intervenção.

Palavras-chave: Trabalho. Processos Identitários. Análise da Atividade

\section{RESUMEN}

El presente artículo tematiza la presencia de los conceptos cotidiano e identidad em las abordajes clínicas del trabajo usualmente designados como Clínica de la Actividad y Ergologia. Propone uma análisis de la relevancia metodológica de esos conceptos para la investigación de situaciones concretas de trabajo. Se argumenta que aunquelos conceptos em cuestión no constituyen conceptos clave em las teorias em análisis, presentan aspectos fundamentales de estos enfoques. Las Clínicas del Trabajo parten de la distinción entre las dimensiones prescrita y real del trabajo, comprendiendo la actividad como las posibilidades de acción del sujeto frente a las prescripciones del trabajo ya los diversos elementos que componen los procesos de trabajo y el contexto organizacional. Esas posibilidades de acción que caracterizan la activida do currenen el cotidiano del trabajo y movilizan recursos identitarios propios a cada sujeto. Así, al evidenciar la importancia de las nociones de cotidiano e identidad se pretende contribuir tanto com el desarrollo teórico de los estudios sobre clínica del trabajo y para sus metodologías de intervención. 
Palabras-clave: Trabajo. Procesos de Identidad. Análisis de la actividad.

\begin{abstract}
This article addresses the presence the concepts of everyday life and identity in the approaches usually designated Clinic of Activity and Ergology and propose an analysis of the methodological relevance of this concepts to research of daily work situations. It is argued that although the concepts in question are not key concepts in the theories under analysis, they present fundamental aspects of these approaches. The Work Clinics, in general, and the approaches here considered in particular, are based on a distinction between the prescribed and actual dimensions of the work, including the activity as the possibilities of action of the subject who works opposite the prescribed amount of work and the various elements that make up the work processes and the organizational context. By highlighting the importance of everyday notions and identity, it is intended to contribute both to the theoretical development of clinical work studies and to their intervention methodologies.
\end{abstract}

Keywords: Work. Identity Processes. Activity Analysis.

\section{Introdução}

Este artigo é um estudo sobre a presença dos conceitos cotidiano e identidade nas abordagens da Clínica da Atividade e da Ergologia. Ambas as abordagens situam-se no que se tem denominado, de forma mais ampla, como Clínicas do Trabalho (Bendassolli \&Soboll, 2011). Tendo como referência os pressupostos teóricos e as metodologias dessas abordagens específicas, busca-se fazer uma análise da relevância dos conceitos cotidiano e identidade para a compreensão dos processos de trabalho. As Clínicas do Trabalho constituem um conjunto de abordagens e estudos sobre o trabalho que enfatiza a importância dos sentidos atribuídos pelos próprios sujeitos nas situações concretas de trabalho bem como as possibilidades de agência nessas situações. Essas abordagens destacam, justamente, a importância das relações interpessoais presentes nas situações cotidianas de trabalho e a capacidade das pessoas se colocarem de forma ativa frente a essas situações. Neste estudo importa identificar como são considerados teoricamente os conceitos de cotidiano e identidade e qual a relevância metodologia desses conceitos para a análise das situações concretas de trabalho.

Há uma longa literatura na filosofia e nas ciências sociais sobre o cotidiano (Heller, 1988, 1994; Tedesco, 1999; Certeau, 2009).
Nas últimas décadas, na psicologia e na antropologia, o cotidiano tem sido um tema de estudo importante, principalmente na sua relação com os processos de trabalho (Spink, 2007; Spink, 2008; Sato \& Souza, 2001; Sato \& Oliveira, 2008). Numa primeira acepção, o cotidiano pode ser compreendido como a dimensão das atividades corriqueiras, do dia a dia, o espaço por excelência da reprodução da ação humana (Heller, 1988). Perspectivas contemporâneas de estudo sobre o cotidiano têm acentuado as aberturas que os indivíduos encontram no cotidiano para a inovação e agência (Tedesco, 1999, Certeau, 2009). Nesse sentido, muito embora seu caráter corriqueiro, o cotidiano constitui-se como o espaço da ação que foge justamente ao prescrito e ao normativo. É no cotidiano que a distância entre a dimensão prescrita do trabalho e o real do trabalho, tal como ele é de fato realizado, se evidencia (Guérin et al., 2001). Ou seja, é no cotidiano que o sujeito encontra as aberturas para, frente a uma impossibilidade da normatividade da experiência, realizar sua ação enquanto sujeito (Schwartz \&Durrive, 2007). Porém, na análise das situações do trabalho, quais elementos estão, de forma específica, relacionadas ao cotidiano? Como a literatura que se debruça sobre as possibilidades de agência do indivíduo no trabalho tem tratado do cotidiano como um tema específico e como uma categoria de análise? Qual a capacidade analítica desse 
conceito para a investigação das situações de agência no contexto do trabalho?

Partindo de uma perspectiva que procura evidenciar as possibilidades de agência do indivíduo no trabalho compreendese que a relação cotidiana que o indivíduo estabelece com seu contexto é necessariamente mediada pelos significados que o indivíduo atribui para sua ação, para a situação em que esta envolvido, para os outros indivíduos e para si mesmo. Aqui, os conceitos de cotidiano e agência articulam-se fortemente ao conceito de identidade. Este trabalho procura incorporar o conceito de identidade para uma compreensão da relação entre cotidiano e agência através da noção de correspondência identitária (Naujorks \&Silva, 2016). Toma-se aqui a identidade como um processo psicossocial de construção de significados e sentimentos de si e dos outros. $\mathrm{Na}$ medida em que estruturado como processo, a identidade realiza-se sincrônica e diacronicamente. A dimensão diacrônica permite apreender a percepção e o sentimento de continuidade proporcionado pela identidade. Da mesma forma, permite apreender as rupturas e descontinuidades, transformações e mudanças. A narrativa biográfica evidencia, justamente, a dimensão diacrônica da identidade. A dimensão sincrônica permite apreender a mútua relação entre as diferentes identidades do sujeito (os diferentes pertencimentos às categorias $\mathrm{e}$ papeis sociais), bem como a existência de identidades salientes nessa diversidade (Stryker, 2000). As relações de trabalho e o cotidiano do trabalho permitem a emergência da vivência da identidade em situação: o trabalho e os pertencimentos organizacionais fazem parte tanto de uma trajetória e uma biografia pessoal (diacronia) quanto da miríade de identidades postas e/ou possíveis (sincronia). As possibilidades de agência pelo indivíduo tendo como referência as percepções e sentimentos identitários passam, em grande medida, pela apresentação cotidiana das contradições inerentes à atividade.

\section{A Clínica da Atividade e a Ergologia}

Nas últimas décadas, duas perspectivas teóricas destacam-se nos estudos que procuram relacionar subjetividade e trabalho e evidenciar, por dentro dessa relação, as possibilidades de agência do sujeito que trabalha: a Clínica da Atividade e a Ergologia. A Clínica da Atividade é uma perspectiva teórica e metodológica desenvolvida tendo como referência os estudos realizados no Centre de Rechercheen Travailet Développment, ligado ao CNAN (Paris). Yves Clot (2006, 2010) e Daniel Fäita (2002; Fäita \&Vieira, 2003) são os principais autores associados a esta abordagem. A Clínica da Atividade situa-se no desenvolvimento da ergonomia francesa (Wisner) e da psicopatologia do trabalho (Le Guillant) e estabelece importantes conexões com o pensamento de Vygotsky, Bakhtin e Oddone (Clot, 2010, Lhuilier, 2011). Para a Clínica da Atividade, a atividade é compreendida como a ação dotada de sentido (Clot, 2006). A noção de atividade enfatiza, dessa forma, a dimensão subjetiva da ação. Em relação ao trabalho, aparece como questão central na Clínica da Atividade a pergunta sobre qual o sentido dado para o trabalho pelo sujeito que trabalha. Assim, ao investigar a atividade, investiga-se a construção de sentidos e significados a partir do trabalho. No contexto das organizações do trabalho, a análise da atividade destaca a relação entre o trabalho prescrito, o trabalho realizado, os sentidos dados e produzidos a partir do trabalho e as intervenções dos trabalhadores, individual e coletivamente nos processos e atividades do trabalho (Telles \& Alvarez, 2004).

A Análise da Atividade parte da distinção, realizada pela ergonomia francesa, entre trabalho prescrito e trabalho real. A atividade de trabalho não pode ser reduzida à prescrição, já que se considera que o trabalho é, de fato, uma tomada de iniciativa para fazer o sistema funcionar (Guérin, 2001). Busca-se assim evidenciar o processo real do trabalho e confrontá-lo com os elementos de prescrição presentes e suas exigências. Distingue-se, então, a tarefa e seu conteúdo prescrito (o resultado antecipado do trabalho); a atividade (a tentativa concreta de realização do trabalho); e, o trabalho (a atividade de 
trabalho, as condições reais e os resultados dessa atividade). Os componentes do trabalho são, então, as condições para sua realização, a atividade e os seus resultados. Além disso, o trabalho possui duas dimensões interrelacionadas: a dimensão pessoal (os significados e sentidos da pessoa envolvida na atividade); e a dimensão social (interpessoal, organizacional e macrossocial).

$\mathrm{Na}$ atividade, acompanhando o seu desenrolar, desvenda-se a relação que o sujeito estabelece com o prescrito e o conjunto das mediações intersubjetivas que lhe dão sustentação. Além disso, o sentido da ação permite que as prescrições e as diversas injunções sociais (dadas pelos outros, pela organização ou, meramente, pela concretude do trabalho) sejam subjetivamente apropriadas. Tal sentido "passa pelos julgamentos feitos e pela recriação dos objetivos visados, que estão além dos objetivos explicitados na prescrição" (Lhuilier, 2011, 43). O sentido da ação, enquanto dimensão pessoal, contradiz, nega e supera as injunções apresentadas pela dimensão social para além das contradições entre o prescrito e o real do trabalho.

Em termos metodológicos, o desenvolvimento da Clínica da Atividade tem como pioneiro o trabalho de Ivar Oddone (et al., 1986). A metodologia da Instrução ao Sósia desenvolvida por ele e sua equipe permite compreender o trabalho a partir das percepções do próprio trabalhador tendo como referência as situações de trabalho. $\mathrm{Na}$ continuidade, Daniel Fäita (2002), destaca a importância de se evidenciar a pluralidade dos pontos de vista produzidos pelos próprios trabalhadores sobre suas situações de trabalho, em um esforço de "estabelecer a relação entre as características observáveis e dedutíveis da atividade verbal e as demais dimensões da atividade em geral" (Faïta, 2002, p.49). Yves Clot (2006, 2010), por sua vez, desenvolve a metodologia da autoconfrontação e da autoconfrontação cruzada para permitir que sejam verificados os diversos sentidos sobre um trabalho que se realiza coletivamente. Para o autor, na análise da atividade é necessário associar os próprios trabalhadores à pesquisa, confrontando-os às sequências de imagens em que eles mesmos aparecem trabalhando.

O dispositivo metodológico é sintetizado pelo autor em três fases (Clot, 2010, 239). Na primeira fase acontece a constituição do grupo de análise (um coletivo voluntário de profissionais), a observação das situações de trabalho e a determinação da sequência de atividade comum para a gravação de um vídeo. Na segunda fase, denominada de autoconfrontação simples, é realizada a gravação em vídeo de uma sequência da atividade e a confrontação do profissional com a gravação em vídeo de sua atividade na presença do pesquisador. $\mathrm{Na}$ terceira fase (autoconfrontação cruzada), acontece a confrontação do mesmo profissional com a gravação feita, na presença do pesquisador e de um colega que já se confrontou com sequências de sua própria atividade. Acontece nesse momento, também, a restituição ao coletivo profissional, sendo essa uma extensão do trabalho de análise. A intervenção, dessa forma, se caracteriza como uma: "procura de meios que permitam ajudar os colectivos de trabalhadores a alargar o seu poder de acção(sic) no e sobre o meio de trabalho real e sobre si mesmos" (Vasconcelos \&Lacomblez, 2005).

As noções de atividade, poder de agir e gênero profissional destacam-se no conjunto da perspectiva da Clínica da Atividade. É na atividade que o indivíduo entra em contato com seus valores e sua trajetória pessoal e profissional, com os outros e com as possibilidades - e impossibilidades - trazidas pela tarefa. "A atividade é o que vincula o indivíduo e o social, o sujeito e a organização do trabalho, os sujeitos entre si e esses sujeitos com os objetos que os mobilizam" (Clot, 2010, 11). Reside aqui a importância do conceito de poder de agir, trazido pela Clínica da Atividade. Tal conceito permite avaliar o "raio de ação efetivo do sujeito ou dos sujeitos na sua esfera de trabalho habitual" (Clot, 2010, 15). O poder de agir relaciona-se, também, como cuidado e a realização de um 
trabalho percebido como bem feito, e daí com um reconhecimento, que pode ser tanto individual quanto coletivo, de uma história profissional e de um compromisso em relação a ela (Clot, 2010, 15).

É o sentido atribuído à atividade que permite ao trabalhador, por meio da atividade, transpor os desígnios do meio, dos outros e das tarefas. Este sentido é construído, no entanto, na relação com os outros. Yves Clot faz uma referência a Leontiev (citado por Clot, 2010): "O homem nunca está sozinho diante do mundo de objetos que o rodeiam. Para se relacionar com as coisas, o traço de união são as relações com os homens" (p. 21).

A dimensão coletiva da atividade remete, portanto, a dois sentidos: a dimensão intersubjetiva dos intercâmbios entre os indivíduos na situação de trabalho e o repertório de ações e regras que constitui cada oficio e que são também nas situações de trabalho historicamente atualizadas (Clot, 2010, 167). É nesse contexto que se torna relevante a noção de gênero profissional. $\mathrm{O}$ gênero remonta à identificação com determinado coletivo: "O gênero de atividades, vinculado a uma situação e a um meio, estabiliza e fixa - nunca de modo definitivo - as maneiras comuns de levar em consideração as coisas e os homens" (Clot, 2010,90). Ou seja, o gênero de atividade coloca o sujeito em contado com a dimensão institucional do trabalho e com um coletivo de trabalho: "No trabalho coletivo, o coletivo de trabalho mobiliza instrumentos genéricos" (Clot, 2010, 167). Mesmo que nem todo trabalho coletivo constitua necessariamente um coletivo de trabalho, o coletivo de trabalho implica, para além da simultaneidade de um conjunto de trabalhadores na situação de trabalho, uma linguagem comum, regras de ofício e a capacidade do coletivo de operar sobre suas próprias regras (Clot, 2010, 167). É na situação de trabalho, na relação com os outros, que essa genericidade do trabalho é apropriada, afirmada e transformada.

Essa apropriação, afirmação e transformação, é, sempre e em certa medida, singular: "Cada sujeito desata e volta a atar, de maneira única, os vínculos estabelecidos entre todas as atividades que ele tentou tornar compatíveis fora dele e em sua história" (Clot, 2010, 31).

É como reconhecimento e afirmação de si na singularização pela atividade que referentes propriamente identitários podem ser mobilizados. Ou seja, é na atividade, nas possibilidades de agência e reconhecimento por ela engendradas, que são atualizados, no cotidiano das relações sociais do trabalho, os referentes identitários. Atualizados, porém, não meramente como demarcadores de uma individualidade, mas como singularização de referentes sociais e coletivos presentes na organização do trabalho e no coletivo de trabalho (o ofício, a categoria profissional). Os sentimentos de pertencimento a uma organização, a uma corporação profissional ou sindicato de trabalhadores, bem como a um de grupo de trabalho (uma equipe vinculada a um setor dentro da organização) constituem os referentes coletivos da identidade individual. $\mathrm{O}$ sujeito encontra nesses referentes as possibilidades do construir e reconhecer seu pertencimento a determinadas coletividades.

Da mesma forma, referentes sociais são postos em evidência. No cotidiano o sujeito estabelece sistematicamente uma relação com as próprias capacidades cuja avaliação pelos outros é tomada como um referente do reconhecimento de si. O reconhecimento do trabalho bem feito, da expertise, do domínio de um oficio, são tomados pelo sujeito como referentes importantes relacionados ao desempenho e aos significados e sentidos do seu papel social. Da mesma forma, julgamentos de si a partir de referentes propriamente idiossincráticos são colocados em tela no cotidiano do trabalho. Valores, a trajetória pessoal, características pessoais, também são referentes apresentados e considerados através das relações de trabalho no reconhecimento que o sujeito elabora sobre si.

A segunda perspectiva das Clínicas do Trabalho a ser considerada é a Ergologia. A abordagem Ergológica desenvolve-se tendo como referência principal os trabalhos de Yves 
Schwartz, professor da Universidade de Provence, onde coordena, desde 1982, o Departamento de Ergologia. Desde então, estudos e intervenções a partir da abordagem ergológica tem sido desenvolvidos por pesquisador de diversos países, entre eles o Brasil (Viegas, 2013). As principais referências para o desenvolvimento da abordagem ergológica são a ergonomia da atividade (Wisner), os estudos realizados por Ganguilhem (2002) sobre saúde e normalidade e os trabalhos do denominado Modelo Italiano (Oddone). A abordagem ergológica tem como objeto de estudo o trabalho sob o ponto de vista da atividade e coloca como foco a capacidade de ação dos trabalhadores nas situações de trabalho (Athayde \& Brito, 2011).

A atividade está diretamente ligada às experiências de singularização que o sujeito encontra na execução do trabalho, nas possibilidades e impossibilidades dessa singularização. Partindo também da distinção operada pela ergonomia francesa entre trabalho prescrito e trabalho real, Yves Schwartz e Louis Durrive (2007) diferenciam o que denominam de Registro 1 (as normas antecedentes) e o Registro 2 (tudo aquilo que diz respeito à resingularização), para pensar os conceitos de infidelidades do meio e usos de si. Com efeito, o meio e os processos de trabalho são sempre infiéis e essa infidelidade deve ser gerida. $O$ sujeito gerencia essa abertura na atividade fazendo um uso de si: do que conhece, do que sabe fazer, das pessoas que pode contar, dos recursos que dispõe. A gerência é a tentativa de controlar os usos que o sujeito faz frente ao caráter imprevisto do meio. Porém, na atividade concreta, as normas antecedentes (entre elas, as normas advindas da gerência) são sempre insuficientes. Esse vazio de normas, ou como lidar com esse vazio de normas, é o que vai determinar as possibilidades de agência do sujeito que trabalha. Assim, "A saúde é a margem de tolerância às infidelidades do meio" (Canguilhem, 2002, 159). Justamente, uma dupla infidelidade do meio: 1 . o meio jamais se repete - ou seja, é impossível padronização absoluta; 2 . qualquer que seja a padronização, ela não pode predeterminar absolutamente a atividade viva. Ou seja, a análise da atividade deve conter uma análise da resingularização, de uma dramática do uso de si.

O trabalho envolve sempre um uso de si, um debate e negociação, onde não existe meramente a execução, mas um uso que o indivíduo é convocado a realizar na atividade. Um uso de si pelos outros, em decorrência das normas, prescrições e valores que constituem determinado trabalho, mas também um uso de si por si, já que as normas, valores e prescrições são recolocadas pelo indivíduo na atividade (Schwartz, 2000).

Os usos de si possíveis são constituídos no cotidiano do trabalho na medida em que, enquanto atividade, o trabalho passa a exigir contínuas ressignificações produzidas pelo sujeito que trabalha.

\section{O Cotidiano}

O cotidiano é a vida do dia a dia, é a reprodução da vida social (Heller, 1988, 20). Heller (1988) identifica dois fundamentos ontológicos do cotidiano: a unicidade e a irrepetibilidade. O cotidiano é a vida de cada um, na medida em que cada um vive na particularidade sua cotidianidade. O cotidiano constitui uma vivência particular, assim, única e irrepetível. Disso decorre a heterogeneidade da vida cotidiana. Esta heterogeneidade é, no entanto, hierarquizada. Em uma determinada época ou cultura, a vida cotidiana gravita em torno de fazeres cotidianos preponderantes, o que envolve a organização do trabalho, os lazeres e o descanso, a vida social, o intercâmbio, etc. Heterogeneidade e hierarquia relacionam-se, coincidindo e proporcionando uma estrutura padrão, conferindo homogeneidade nos processos de reprodução social em uma determinada estrutura social.

Heterogeneidade e hierarquia contextualizadas histórica e socialmente são, então, as primeiras características dos fazeres cotidianos. Tomando-se um indivíduo particular, este indivíduo se deterá, no curso de um único dia, com fazeres diversos e haverá um e outro dentre eles preponderantes, não só para este indivíduo particular, mas para 
sua classe social e para sua época histórica (Heller, 1998).

Dessa forma, o cotidiano é onde, na vida de cada um, a genericidade da vida social assume sua dimensão particular e é vivida nessa particularidade. $\mathrm{O}$ particular é o que se apresenta como único, específico, irrepetível. Toda ação humana, porém, na medida em que se dá na relação com os outros, é uma ação da genericidade humana.

Para Heller há uma relação intrínseca entre a particularidade e a genericidade:

$\mathrm{O}$ indivíduo (a individualidade) contém tanto a particularidade quanto o humano genérico que funciona consciente e inconsciente no homem. Mas o indivíduo é um ser singular que se encontra em relação com sua própria individualidade particular e com sua genericidade humana; e, nele, tornam-se conscientes ambos os elementos (1998, p. 22).

A unidade entre particularidade e genericidade é uma condição ontológica, vivida para todos "nem sempre na mesma proporção, nem tampouco com a mesma extensão", como um "muda unidade vital" (Heller, 1998, 23). Muda, no sentido de tão problematizada, não colocada como questão.

A vida cotidiana é, então, o contexto da particularidade. Contexto onde o indivíduo apreende-se no conjunto de suas relações sociais, habilita-se a elas e se mantém enquanto indivíduo. Muito embora imprescindível, restringir-se à cotidianidade impossibilita ao homem constituir-se a partir da humanidade enquanto genericidade. Para Heller (1998), transcender a cotidianidade torna-se uma necessidade humana.

Heller identifica duas formas de elevação acima da vida cotidiana: a ciência e a arte. Isto porque em ambas a tendência espontânea do pensamento cotidiano é substituída pelo resultado duradouro de suas objetificações. Ciência e arte produzem como resultado objetos incorporado pela humanidade toda (Heller, 1998, p. 26). A objetificação permite colocar em questão aspectos do cotidiano naturalizados e vividos espontaneamente. Permite, assim, evidenciar as relações e os processos sociais que lhe são constitutivos e sua expressão particular, cotidiana.

A reprodução social do homem particular é a reprodução social do homem concreto(com um trajetória biográfica particular, com valores e sentidos pessoais, que ocupa um lugar determinado na divisão social do trabalho, etc.).Além disso, a conservação do particular na vida cotidiana, enquanto autoreprodução, é um momento da reprodução da sociedade. Assim, a vida cotidiana constitui-se no espaço da interrelação entre a particularidade concreta da vida de cada homem e a generalidade das relações e da vida social. A vida cotidiana remete, então, à forma imediata da generalidade. Estabelecer as contiguidades, não as semelhanças, entre os diferentes fazeres cotidianos, permite evidenciar os processos sociais que engendram e dão sustentação a cada fazer cotidiano, em particular. As contiguidades estabelecem, sincrônica e diacronicamente, o conjunto dos fazeres tornados cotidianos. Como contiguidade, as atividades se estendem,se encadeiam, formando a totalidade do processo de reprodução, tanto para um individuo em particular como para determinado grupo em determinada época (Heller, 1994).

Certeau (2013), em A Invenção do Cotidiano, evidencia como as pessoas podem enfrentar o subjugo a que estão cotidianamente submetidas utilizando-se de procedimentos minúsculos, corriqueiramente engendrados $\mathrm{e}$ que jogam, ao final, com os mecanismos de disciplina e controle presentes nos processos sociais,procurando em alguma medida alterálos. Para o autor, há uma série de 'maneiras de fazer' que formam uma contrapartidado lado dos dominados, fazeres não problematizados mas que organizam formas reticulares de resistência e de ação. O cotidiano revela-se, 
então, um jogo no qual o trabalhador transforma e adapta os mecanismos de disciplina, ordenamento e subordinação.

Certeau denomina de "maneiras de fazer" a esse processo de reapropriação do espaço organizado, que altera o funcionamento das estruturas tecnocráticas e que acontece por uma "multiplicidade de 'táticas' articuladas sobre os 'detalhes'do cotidiano" (2013, p. 41). A tática aponta para aquilo que é mobilizado no cotidiano, na relação direta com o outro, no caráter imediato da ação. Diferente da estratégia, que pressupõe o sujeito distanciado, que define um campo, objetivos e calcula sua ação e avalia os resultados, a tática é imediata tanto em relação a ação quanto em seus resultados (2013, p.45). A tática é, por excelência, a possibilidade da ação no cotidiano.

Para além de um conjunto de procedimentos estereotipados, as maneiras de fazer indicam formas próprias de ação de um determinado grupo, usos próprios a partir das normatizações, regras e disciplinamentos (Certeau, 2013, p. 87). Certeau indica a importância de se localizar e distinguir estratégias, tipos de operações, esquemas de operações e maneiras de fazer. São nas maneiras de fazer, por dentro das estratégias voltadas para a técnica e a eficácia, por dentro das operações que realizam tais estratégias, que os usos podem revelar um estilo de ação, a identificação com um grupo ou um lugar, instaurar a pluralidade e a criatividade. Seguindo a comparação com a linguística, realizada por Certeau, pode-se pensar que as estratégias e os tipos e esquemas de operações fornecem os "contextos de uso" (a língua, a partir da distinção entre língua e palavra, tal qual apresentada por Saussure) (Certeau, 2013, p. 90) e táticas fornecem o campo para a ação, as maneiras de fazer, o uso. É no cotidiano, frente ao peso da estrutura e dos processos de reprodução social, que a tática se torna possível. "A tática é a arte do fraco", diz Certeau (2013, p. 95). Justamente, é a ação possível daquele que não tem o domínio do campo, que não define as operações, que não é o sujeito da estratégia, que não compartilha do objetivo.

$\mathrm{Na}$ Clínica da Atividade e na Ergologia, o cotidiano configura o momento e o espaço onde o sujeito é confrontado com seu trabalho, onde as estratégias da gerência e suas operações aparecem como um campo a ser problematizado pelo sujeito. A relação com os outros, com o coletivo de trabalho,com o ofício (enquanto papel a ser desempenhado e gênero de atividade a ser atualizado), com as infidelidades do meio e, ao mesmo tempo, com as possibilidades de inovação e agência se dão no cotidiano de trabalho. Assim, são nas distintas configurações cotidianas do trabalho que se abrem as possibilidades de expressão do sujeito, que emergem suas táticas. É por sua objetificação que o cotidiano pode se tornar objeto de reflexão e então de superação de sua naturalização e espontaneismo.

É no cotidiano que se apresenta ao trabalhador o real do trabalho, sua dimensão concreta. Essa dimensão, numa inflexão à tradição da ergonomia, não é vista meramente como o conjunto das constrições do ambiente ou dos processos de trabalho, ou seja, como externas ao sujeito, mas como modificação dessas condições pelo sujeito. "O real é a ação de realização - jamais totalmente previsível que põe o sujeito em contato com as realidades objetivas do mundo das coisas e dos homens, ocasiões para, e obstáculos ao[,] seu desenvolvimento" (Clot, 2006, p.93. Colchetes no original).

Para Yves Schwartz, é "no interior das coerções materiais e sociais e trabalhando-as, [que] se abre o espaço para uma gestão diferenciada de si mesmo" (2000, p. 37). Assim, mesmo as constrições e exigências objetivas do trabalho (podendo-se acrescentar as relações de trabalho e o contexto organizacional), encontram no indivíduo as virtualidades que singularizam as situações cotidianas do trabalho. É justamente no cotidiano que emerge para o trabalhador o questionamento sobre seu papel e suas 
possibilidades de ação. E é na dimensão coletiva do trabalho que esse questionamento pode ser remetido ao coletivo de trabalhadores do qual faz parte e ao oficio do qual participa.

O cotidiano constitui, dessa forma, as situações que possibilitam uma expressão singular, ao mesmo tempo pessoal e coletiva. Yves Schwartz, tendo como referência o contexto industrial, afirma que o coletivo de trabalho, a equipe, proporciona, no cotidiano, o "lugar de uma alquimia sempre aleatória onde histórias e vidas singulares buscam se exprimir positivamente nos atos coletivos informais" (2000, p. 38).

\section{Identidade e Correspondência Identitária}

Os estudos sobre identidade têm enfatizado pelo menos três características associadas ao fenômeno: primeiro, que a identidade não implica em uma essência do ser, algo que o defina enquanto substância, mas, ao contrário, um processo eminentemente relacional e inacabado, onde $\mathrm{o}$ outro desempenha um papel fundamental; segundo, a necessidade de abordagens que integrem diferentes perspectivas de análise, com destaque para aquelas que procuram relacionar as dimensões pessoal, social e coletiva da identidade; por fim, a identidade tomada com um conceito que remete a processos cognitivos e afetivos de reconhecimento de si e dos outros, tanto individual quanto coletivo (Jenkis, 1996).

Toma-se aqui a identidade como um conjunto de processos cognitivos e afetivos, de construção e atribuição de significados que pessoas, individual e coletivamente, elaboram sobre si mesmo, outras pessoas, grupos e a sociedade a partir de referentes identitários pessoal e socialmente construídos (Naujorks \& Silva, 2016). Considerando-se o mundo do trabalho, tais referentes identitários são constituídos pelos valores e sentidos pessoais atribuídos ao trabalho, a trajetória de cada pessoa e a sua formação para o trabalho, as relações interpessoais mediadoras do trabalho e a inserção da pessoa no local do trabalho e no contexto organizacional. Tais referentes podem ser compreendidos a partir da distinção, elaborada por diferentes teorias da identidade, entre as dimensões pessoal, social e coletiva da identidade individual (Brewer \&Gardner, 1996; Brewer, 2001; Onorato \&Turner, 2001; Owens; Robinson \&SmithLovin, 2010).

A dimensão pessoal da identidade abrange os referentes idiossincráticos e a trajetória biográfica. Constitui tal dimensão os valores construídos ao longo da formação do indivíduo, o conjunto das vivências vinculadas à trajetória biográfica e às outras pessoas tornadas significativas, principalmente na primeira infância, o autoconceito e, a partir dele, a autoestima. Diferentes abordagens e perspectivas teóricas tem abordado a dimensão propriamente pessoal da identidade individual, notadamente a psicanálise (Freud, 1921/1976), as psicologias do ego (Erikson, 1968/1976) e as teorias próximas ao cognitivismo e ao cognitivismo social (Leary \&Tangney, 2003; Hitlin, 2003).

Os sentimentos e os significados decorrentes de um reconhecimento de si como pessoa única são a principal característica da dimensão pessoal da identidade. Esse conhecimento de si é produzido tanto a partir da cultura e dos grupos sociais dos quais o indivíduo participa, quanto pelos processos estritamente pessoais de formação da personalidade (Mucchielli, 1994, p. 25). As identificações afetivas constituídas ao longo da infância e juventude intervêm nas percepções de cada pessoa em relação aos outros e ao mundo social. Esse aspecto afetivo da identidade atualiza-se por intermédio dos processos de identificação também no contexto das organizações e das relações de trabalho, constituindo um processo fundamental para o reconhecimento do sujeito no contexto do trabalho e para a manutenção do autoconceito, construído ao longo da trajetória pessoal.

A construção do autoconceito a partir dos processos identitários pode ser entendido como a emergência de um conjunto relativamente coerente de pensamentos e 
sentimentos que uma pessoa elabora acerca de si-mesma e de suas objetificações (Owens, Robinson \&Smith-Lovin, 2010). O autoconceito envolve os pensamentos, sentimentos e imaginações da pessoa sobre ela mesma, uma visão idealizada de si e, também, uma avaliação sobre como é vista pelos os outros (Stets \&Burke, 2003). A autoestima é um dos componentes do autoconceito e os dois constituem a identidade pessoal. A autoestima diz respeito ao valor que a pessoa atribui a si mesma. Duas dimensões estão presentes na autoestima diretamente relacionadas com os processos de trabalho e com o reconhecimento a partir da identidade: sentir-se capaz e sentirse aceito (Stets \&Burke, 2003, 131).

Através da manutenção do autoconceito e da autoestima nas relações de trabalho, da possibilidade de afirmação dos valores pessoais e do reconhecimento de uma coerência em relação à trajetória pessoal, a identidade pessoal pode adquirir relevância para o sujeito e encontrar correspondências nas dimensões social e coletiva da identidade.

A dimensão social da identidade constitui-se a partir dos referentes relacionados a categorias e papeis sociais. Categorias sociais dizem respeito a classificações amplas socialmente produzidas em relação às quais as pessoas estão geralmente submetidas, como raça, gênero, etnia, entre outras. Papéis sociais dizem respeito ao desempenho de funções sociais no contexto de uma sociedade hierárquica e especializada. A identidade social remete ao compartilhamento de atributos que não são propriamente pessoais, mas que implicam em de características, pautas de conduta e referencias interpretativas que aproximam cada individuo a grupos sociais pelas categorias sociais ou papeis sociais que compartilham. Duas perspectivas teóricas tematizam, de forma específica, a identidade social: as abordagens cognitivistas (Tajfel, 1982) e o interacionismo simbólico estrutural (Stryker, 1981).

A identidade social provê para a pessoa identificações com uma série de características, expectativas, costumes, crenças e ideologias próprias aos grupos e categorias sociais específicas. Ela também produz enlaces diretamente relacionados aos papeis sociais associados às relações familiares, às relações pessoais próximas e às diversas funções sociais. Em uma perspectiva interpessoal, a identidade social evidencia os aspectos de interdependência das relações com os outros, interpendências fundadas nas expectativas de desempenho dos papéis sociais e nos valores e significados atribuídos às categorias sociais. Expectativas reciprocas de comportamento orientam as avaliações sobre desempenho e as adequações às categorizações sociais (Brewer, 2001; Tajfel, 1982). Em relação ao trabalho, a identidade social liga-se diretamente à noção de identidade profissional.

A identidade profissional é uma dentre as várias identidade sociais possíveis(Dubar, 2005). A trajetória biográfica e as relações interpessoais provêm referentes importantes para a construção e manutenção da identidade profissional. A escolarização, a formação profissional, a formação em um oficio, a inserção no contexto organizacional, a realização de atividades profissionais, as relação com os colegas de trabalho, todos esses elementos constituem referentes relevantes para a elaboração pelo sujeito de um reconhecimento de si a partir do trabalho. Tais referentes podem corresponder aos valores tomados como pessoais, aos sentidos e sentimentos atribuídos a si, à percepção de coerência em relação à trajetória pessoal.

A dimensão coletiva da identidade, por sua vez, refere-se aos sentidos e sentimentos de pertencimento a uma ou mais coletividades. Frequentemente tais sentimentos decorrem da identidade social, muito embora não se restrinjam a ela. A identidade coletiva diferencia-se da identidade social justamente pelos vínculos e sentimentos de pertencimento e compromisso a um grupo particular. A identidade profissional, por exemplo, não denota a priori nenhum compromisso com a coletividade que compõe tal categoria profissional. A identidade coletiva, no entanto, remete ao vínculo e aos sentimentos de 
pertencimento a um grupo profissional específico, uma associação profissional, a um sindicato ou, até mesmo, a uma empresa. No mundo do trabalho, a dimensão coletiva da identidade é geralmente abordada nos estudos sobre identidade organizacional (Meyer \& Allen, 2007).

A identidade coletiva diz respeito a uma percepção entre os membros de uma determinada coletividade do compartilhamento de uma mesma identidade (ou, mais propriamente, de um conjunto específico de referentes identitários), de uma vivência conjunta, do envolvimento em uma de uma mesma realidade e destino (Owens, Robinson \& Smith-Lovin, 2010, 490). Dessa forma, a identidade coletiva se refere a um processo mais inclusivo que a identidade social, permitindo a formação de um 'nós', ou seja, um coletivo que se reconhece como tal.

O conceito de identidade coletiva, tal como vem sendo trabalho pela sociologia, relaciona-se fortemente à noção de ação coletiva. Muito embora o forte conteúdo normativo associado à noção de identidade coletiva, principalmente nos estudos sobre movimentos sociais no Brasil (Silva, 2010), a identidade coletiva tem sido um conceito útil para a compressão dos processos de formação dos atroes sociais. Para Alberto Melucci (1996, 70 itálicono original) a identidade coletiva é vista como "uma definição compartilhada produzida por um número de indivíduos (ou grupos em um nível mais complexo) sobre as orientações de suas ações e o campo de oportunidades e constrangimentos no qual suas ações acontecem". A capacidade de agir coletivamente de forma unificada e coerente pressupõe certa reflexividade que $\mathrm{o}$ ator realiza acerca de si mesmo, sobre os outros atores, o campo social compartilhado e os desafios e objetivos a se perseguir. Em relação à atividade, referentes relacionados ao coletivo remete às possibilidade da construção de significados comuns através dos quais a ação social, a coletivização e a mudança ou transformação do contexto social apareçam como relevantes, significados esses que possam ser colocados pelos atores sociais em uma perspectiva de mudança ou transformação social.

As dimensões identitárias apresentadas são, sobretudo, um recurso analítico que permite abordar a complexidade do fenômeno identitário. Cada uma delas coloca em evidencia aspectos de um sujeito que, em todo caso, deve ser tomado em sua totalidade. Ao longo da trajetória profissional e do trabalho, determinados referentes torna-se salientes, adquirindo destaque em relação a outros referentes de uma mesma dimensão identitária (Stryker, 2007). O conceito de correspondência identitária procura evidenciar os entrelaçamentos entre os referentes salientes dessas distintas dimensões identitárias (Naujorks \&Silva, 2016). Pode-se supor que a presença de referentes correspondentes entre si em cada uma dessas dimensões permite vincular ao reconhecimento identitário percepções e sentimentos de uma coerência de si.

Considerando-se novamente o mundo do trabalho, a correspondência identitária pressupõe um alinhamento e uma convergência de referentes relacionados aos valores pessoais, ao autoconceito e à trajetória biográfica associada ao trabalho e à vida profissional (identidade pessoal), ao desempenho do papel profissional (identidade social) e aos sentimentos de pertencimento ao coletivo de trabalho (grupo de colegas, equipe de trabalho, sindicato, organização, etc).

Tais referentes são apresentados aos sujeitos nas situações cotidianas de trabalho, porém com diferentes saliências. Yves Clot (2010, 33) destaca que a heterogeneidade interna (sic) do sujeito, base de sua dinâmica psíquica, nunca é mobilizada de uma só vez. De fato, no cotidiano do trabalho, nas diversas atividades, situações particulares engendram referentes com diferentes significados, cujos sentidos estarão vinculados a diferentes dimensões identitárias. 
Tendo como referência os trabalhos precursores de Le Guillant, Yves Clot destaca que a identificação joga um papel fundamental na relação entre vida social e vida subjetiva. Para aquele autor, a identificação envolve tanto um laço com alguém diferente (ser pessoal) quanto com um sentido coletivo do trabalho (ser social), afirmada esta última pela "dignidade do oficio no estabelecimento de relações autênticas com o real" (Clot, 2010, 79). O "ser pessoal" da identificação remete aos valores e à trajetória biográfica que na relação com o outro são reconhecidas e que servem, por isso, para o autoreconhecimento. A dimensão pessoal da identidade pressupõe, então, o reconhecimento pelo outro na situação de trabalho dos valores e da trajetória pessoal. O "ser social" da identificação remete ao reconhecimento mediado pelo coletivo da categoria e do papel profissional desempenhado.

Para Yves Clot (2006, p. 95) "a atividade de trabalho faz parte de uma constelação de atividades pessoais em intersignificação". Aqui, sustenta-se que tais atividades não estão desconectadas. Ao contrário, se considerarmos os processos identitários, as correspondências entre os referentes presentes nas múltiplas dimensões identitárias são significativas para a realização do trabalho enquanto atividade.

O trabalho é sempre uma prova, entendendo-se pelo termo uma situação que não oferece todas as repostas às questões que ela mesma levanta: uma situação que convoca o sujeito, remetendo-os aos outros, a si mesmo, ao objeto de seu trabalho e a seus instrumentos de ação e, por fim, aos esperados genéricos de sua atividade (Clot, 2006, p. 111).

O sujeito procura fazer prevalecer na atividade do trabalho o sentido de sua existência, mesmo que esse processo não lhe seja totalmente ou de alguma forma transparente. Ele o faz, no entanto, em uma situação de trabalho. Yves Clot (2006, p. 97), ao delimitar a unidade de análise da atividade de trabalho, por ele denominada de atividade dirigida, diferencia três componentes: a atividade dirigida pelo sujeito que realiza a atividade; a atividade dirigida pelo objeto da tarefa e a atividade dirigida pelos outros. O gênero de atividade é um mediador desse conjunto que caracteriza a atividade dirigida. $\mathrm{O}$ gênero de atividade tem como uma de suas características essenciais apresentar os traços que definem determinada atividade. $\mathrm{Na}$ atividade, o gênero é apropriado e recolocado. É nessa atualização do gênero que se encontra a atividade triplamente dirigida: pelo sujeito, pelo objeto e pelos outros (Clot, 2006, p. 97). Essa atualização tem como ponto de partida os conflitos frente às injunções do objeto, dos outros e do próprio sujeito. A atividade de trabalho é sempre, em alguma medida, a busca por um equilíbrio, mesmo que temporário, frente a essas múltiplas injunções. Ela é, para usar a expressão de Certeau (2013), o conjunto das táticas, dos usos, frente a essas injunções.

Tais processos de reconhecimento acontecem tendo como contexto as situações cotidianas de trabalho. Yves Schwartz (2000) evidencia que, para além dos aspectos técnicos e burocráticos do trabalho, o cotidiano do trabalho institui um espaço de singularização das relações sociais. $\mathrm{O}$ desempenho do papel social e do oficio, a capacidade técnica, a relação com os colegas permitem que o si mesmo, os outros e o trabalho, sejam colocado mutuamente em questão. Instaura-se uma singularização por dentro dessas distintas dimensões.

Por trás de toda vida profissional, de toda mutação do conteúdo do trabalho, se perfila um problema de coerências individuais, no qual a percepção do "oficio" aparece determinante. Se o trabalhador em equipe não retoma seu oficio, ele pode se sentir excluído desta cadeia que liga seu destino aos que decidem e vivem o cotidiano; e viver em ruptura a vida familiar e a vida em 
equipe, doravante incomunicáveis (Schwartz, 2000, p. 39).

A percepção e o sentimento de pertencimento ao coletivo de trabalho acontece pela sua inserção, através do ofício, a essa coletividade. É no cotidiano do trabalho que tal inserção é percebida e que tal coerência vivida. A vivência dessa coerência, entre o papel social (identidade social) e o pertencimento coletivo (identidade coletiva), torna-se fundamental quando determinados valores pessoais e a trajetória profissional pessoal aparecem como salientes, de tal forma que isto se torna, "condição para viver melhor em coerência a vida social e a vida familiar e a vida pessoal" (Schwartz, 2000, p. 39).

\section{Considerações Finais}

A procura pelos referentes identitários nas situações concretas de trabalho como demarcadores das relações entre os sujeitos e em relação à atividade e à organização tornase particularmente relevante para se compreender reconhecimento no trabalho e, por extensão, as possibilidades de agência. Tais referentes não são, no entanto, suficientes per se. Yves Clot (2010) destaca que a percepção de autenticidade no trabalho não acontece apenas pelo reconhecimento no coletivo do trabalho, mas na correspondência desse reconhecimento com o ser pessoal da identificação com o trabalho. De forma semelhante, Schwartz (2000) evidencia que a coerência entre os sentidos atribuídos ao coletivo de trabalho e as regras do oficio e os sentidos atribuídos pelo sujeito à atividade no contexto relacionam-se diretamente com as possibilidades de um uso de si na atividade e, por conseguinte, de singularização no trabalho.

Com efeito, é na presença múltipla do sentido - e na sua possibilidade de reconhecimento - que a atividade do sujeito apresenta uma abertura em relação ao seu poder de agir. Tal reconhecimento precisa, em alguma medida, abarcar a multiplicidade dos sentidos mobilizados nas dimensões pessoal, social e coletiva da atividade. $\mathrm{O}$ reconhecimento identitário $\quad-\quad$ e a correspondência entre suas múltiplas dimensões - parecem constituir, dessa forma, um processo fundamental para a construção do sentido e da agência na atividade.

\section{Referências}

Athayde, Milton \&Brito, Jussara (2011).

Ergologia e Clínica do Trabalho. In:

Bendassolli, P. E. \&Soboll, L. A. Clínicas

do Trabalho. São Paulo: Atlas.

Bendassolli, Pedro. E. \&Soboll, Lis Andrea.

(2011). Introdução às clínicas do trabalho.

Aportes teóricos, pressupostos e aplicações.

In: Bendassolli, P. E. \&Soboll, L. Clínicas

do Trabalho. São Paulo: Atlas.

Brewer, Marilynn B. \& Gardner, Wendi

(1996). Who is the "We"? Levels of

Collective Identity and Self

Representations. Journal of Personality and

Social Psychology. v. 71, n. 1, p. 83-93.

Brewer, Marilynn B. (2001).The Many Faces

of Social Identity: implications for political psychology. Political Psychology. v. 22, n. 1, p. 115-125.

Canguilhem, Georges (2002). O Normal e o Patológico. Rio de Janeiro: Forense Editora.

Certeau, Michel de (2013). A invenção do cotidiano. 1. Artes do fazer. $20 \mathrm{Ed}$. Petrópolis: Vozes. Ed. original de 1990.

Clot, Yves. (2006). A Função Psicológica do Trabalho. Petrópolis, Rj: Vozes.

Clot, Yves. (2010). Trabalho e Poder de Agir. Belo Horizonte, Belo Horizonte: Fabrefactum.

Dubar, Claude. (2005). A Socialização. Construção das Identidades Sociais e Profissionais. São Paulo: Martins Fontes.

Erikson, Erik. (1976). Identidade: juventude e crise. Rio de Janeiro: Zahar Editores. Edição original de 1968.

Faïta, Daniel. (2002). Análise das práticas linguageiras e situações de trabalho: uma renovação metodológica imposta pelo objeto. In: Maria Cecilia Souza-e-Silva \& Daniel Fäita. Linguagem e Trabalho. Construção de objetos de análise no Brasil 
e na França. São Paulo: Cortez Ed.

Faïta, Daniel; Vieira, Marcus. (2003).

Reflexões metodológicas sobre a autoconfrontação cruzada. Delta. São Paulo, v. 19, n. 1.

Freud, Sigmund. (1976). Psicologia de Grupo e Análise do Ego. Edição Standart das Obras Psicológicas Completas de Sigmund Freud. V. XVIII. Rio de Janeiro: Imago Editora. Original publicado em 1921.

Guérin, François; Laville, Antoine; Daniellou, François; Duraffourg, J.; Kerguelen, A. (2001). Compreender o trabalho para transformá-lo. A prática da ergonomia. São Paulo: Editora Edgard Blücher.

Heller, Agnes. (1988). O cotidiano e a história. São Paulo: Paz e Terra. Edição original de 1970.

Heller, Agnes. (1994) Sociologia de la Vida Cotidiana. 4. Ed. Barcelona: Ediciones Península.

Hitlin, Steven. (2003). Values As The Core of Personal Identity: Drawing Links Between Two Theories of Self. Social Psychology Quarterly, v. 66, n. 2, p. 118-137.

Jenkins, Richard. (1996). Social Identity. New York, Routledge.

Leary, Mark R.; Tangney, June Price (2003).The Self as an Organizing Construct in the Behavioral and Social Sciences. In: Leary, M. R.; Tangney, J. P. (eds.). Handbook of Self and Identity. New York: The Guilford Press.

Lhuilier, Dominique. (2011). Filiações

Teóricas das Clínicas do Trabalho. In:

Bendassolli, P. E. \&Soboll, L. A. Clínicas do Trabalho. São Paulo: Atlas.

Meyer, John P. \& ALLEN, Natalie J. (2007). Commitment in the Workplace. Theory, research and application. Thousand Oaks, CA: Sage.

Melucci, Alberto. (1996). Challenging Codes - Collective Action in the Information Age. Cambridge: University Press.

Mucchielli, Alex. (1994). L'Identité. 3. Ed. Paris: Press Universitaire de France. Naujorks, Carlos J. \&Silva, Marcelo K. (2016). Correspondência Identitária e Engajamento. Civitas. Porto Alegre, v. 16, n. 1, jan-mar, p. 136-156.
Oddone, Ivar (et al.) (1986). Ambiente de Trabalho. A luta dos trabalhadores pela saúde. São Paulo: Hucitec.

Onorato, Rina S.; Turner, John C. (2001). The "I", the "Me" and the "us": The psychological group and self-concept maintenance and change. In: Sedikides, C.; Brewer, M. B. (orgs) Individual Self, Relational Self, and Collective Self. Philadelphia: Psychology Press.

Owens Timothy J.; Robinson Dawn T.; SmithLovin. Lynn (2010). Three Faces of Identity. Annual Review of Sociology. v. 36, p. 477-99

Sato, Leny. \&Oliveira, Fábio de (2008). Compreender a gestão a partir do cotidiano de trabalho. Aletheia, v. 27, p. 188-197.

Sato, Leny. \& SOUZA, M. P. R. de (2001). Contribuindo para desvelar a complexidade do cotidiano através da pesquisa etnográfica em Psicologia. Psicologia USP, 12(2).

Schwartz, Yves \&Durrive, Louis (2007). Trabalho e Ergologia: conversas sobre a atividade humana. Niterói: Universidade Federal Fluminense.

Schwartz, Yves (2000). Trabalho e usos de si. Pro-posições, v. 1, n. 5. (32), Julho.

Silva, Marcelo Kunrath. (2010). De volta aos movimentos sociais? Reflexões a partir da literatura brasileira recente. Ciências Sociais Unisinos, v. 46, n. 1, p.2-9.

Spink, Mary. J. P. (2007). Pesquisando no cotidiano: recuperando memórias de pesquisa em Psicologia Social. Psicologia \& Sociedade, 19(1), p. 07-14.

Spink, Peter. K. (2008). O pesquisador conversador no cotidiano. Psicologia \& Sociedade, 20, p. 70-77.

Stets, Jan E.; Burke, Peter J. (2003) A Sociological Approach to Self and Identity. In: Leary, Mark R.; Tangney, June P. Handbook of Self and Identity. New York: The Guilford Press.

Stryker, Sheldon (1981). Social Psychology.Trends, assessment and prognosis. American Behavioral Scientist, v. 24, n. 3, January/February, p. 386-406.

Stryker, Sheldon. (2000). Identity competition: 
key to differential social movement participation. In: Sheldon Stryker; Timothy J. Owens; Robert White. Self, Identity, and Social Movements. Minnesota: University of Minnesota Press.

Stryker, Sheldon. (2007). Identity theory and personality theory: mutual relevance.

Journal of personality, v. 75 , n. 6 , December.

Tajfel, Henri. (1982). Grupos Humanos e Categorias Sociais. Estudos em psicologia social, vols. 1 e 2. Lisboa: Livros Horizonte.

Tedesco, João C. (1999). Paradigmas do cotidiano: introdução à constituição de um campo de análise social. Santa Cruz do Sul: EDUNISC.

Telles, Ana L.\&Alvarez, Denise. Interfaces ergonomia-ergologia: uma discussão sobre trabalho prescrito e normas antecedentes. In: Figueiredo, M. Athaíde, M. Brito, J.Alvarez, D. (Org.) Labirintos do trabalho: interrogações e olhares sobre o trabalho vivo. Rio de Janeiro: DP\&A, 2004, p. 63-90.

Vasconcelos, Ricardo \&Lacomblez, Marianne. (2005). Redescubramo-nos na sua experiência: O desafio que nos lança Ivar Oddone. Laboreal. v. 1, n. 1, p. 38-51.

Recuperado em http://laboreal.up.pt/revista/artigo.php?id=3 7t45nSU5471122647:5:23351.

Viegas, Moacir. (2013). Histórico e conceitos da ergologia. Entrevista com Yves Schwartz. Reflexão e Ação, v. 21, n.1.

Dados sobre o autor:

- Carlos José Naujorks é Psicólogo (UFSC), mestre em sociologia política (UFSC), doutor em sociologia (UFRGS), professor do Departamento de Psicologia da Universidade Federal de Santa Catarina (UFSC). 